\title{
Effect of selected bisphenol derivatives on nuclear receptor expression in ovarian cell line COV434
}

\author{
Alzbeta Bujnakova Mlynarcikova, Sona Scsukova \\ Institute of Experimental Endocrinology, Biomedical Research Center, Slovak Academy of Sciences, Bratislava, Slovakia \\ E-mail: ueenmly@savba.sk
}

\begin{abstract}
Objectives. Bisphenol A (BPA), as an indispensable plastic additive, has also been proven as an endocrine disruptor associated with adverse health effects including impaired ovarian function and cancer. Due to the restrictions of its usage, several analogs have been employed to replace BPA. Although many studies revealed a harmfulness in the biological effects of BPA analogs, their specific targets remain largely unknown. Nuclear receptors (NRs) may be one of the most important targets of bisphenols. Therefore, in this study, our attention was directed to explore the effect of BPA and its analogs, AF and $\mathrm{S}$, on the mRNA expression of selected NRs involved in the steroidogenic and carcinogenic pathways in the human granulosa cell line COV434. The NRs investigated included: thyroid hormone receptor $\alpha$ (THRA), peroxisome proliferator activating receptor $\beta / \delta$ (PPARD), retinoid X receptor a (RXRA), chicken ovalbumin upstream promoter-transcription factor II (COUPTFII), nuclear receptor-related protein 1 (NURR1), and liver receptor homolog-1 (LRH1).

Methods. COV434 cells were treated with the bisphenols at the concentrations of $10^{-9} \mathrm{M}, 10^{-7} \mathrm{M}$, and $10^{-5} \mathrm{M}$, and after 24 and $48 \mathrm{~h}$, cell viability was monitored by the MTS assay and gene expressions were analyzed using RT-qPCR.

Results. Bisphenol treatment did not alter the COV434 cell viability. After $24 \mathrm{~h}$, the expression of neither of the NRs was changed. Likewise, after $48 \mathrm{~h}$, the expression of the selected genes was not altered. However, both BPAF and BPS increased, at the highest concentration $\left(10^{-5} \mathrm{M}\right)$ used, the mRNA levels of both PPARD and NURR1 NRs after $48 \mathrm{~h}$ of the treatment. In the BPA-treated groups, no significant upregulation was observed.

Conclusions. In the present study, the effect of bisphenols on COUP-TFII, Nurr1, and LRH-1 NRs was investigated for the first time. Although generally we did not observe that BPs provoked any alterations in the expression of the selected NRs in COV434 cells, at specific concentrations and time points they might alter mRNA expression of certain NRs (NURR1, PPARD).
\end{abstract}

Key words: Bisphenol A, Bisphenol analogs, nuclear receptors, granulosa cell line COV434

Bisphenol A (BPA) belongs to the indispensable agents in the manufacture of plastics. It is present in polycarbonate plastics and epoxy resins, food storage containers and cans, thermal paper receipts, dental fillings, etc. (Gerona et al. 2016). The ubiquitous presence of BPA has been confirmed in $90-100 \%$ of population samples including ovarian follicular fluid (Gerona et al. 2016; Cao et al. 2018).
Numerous studies have reported that BPA has a broad range of endocrine disrupting properties and have suggested a link between an increased BPA exposure to a range of chronic health conditions, including metabolic and reproductive disorders, cardiovascular diseases or various types of cancer (Scsukova et al. 2016; Nomiri et al. 2019; Castellini et al. 2020). The literature data have also indi-

Corresponding author: Alzbeta Bujnakova Mlynarcikova, PhD., Institute of Experimental Endocrinology, Biomedical Research Center SAS, Dubravska cesta 9, 84505 Bratislava, Slovakia; phone: +4212 32295 275; e-mail: ueenamly@savba.sk. 
cated that BPA exerts its biological effects in both normal and cancer tissues through deregulation of signaling pathways associated with the cell proliferation, differentiation, and migration. It has also been revealed that BPA is an ovarian toxicant and might be linked to disrupted estrous cyclicity, higher risk of miscarriage or polycystic ovarian syndrome (Lathi et al. 2014; Peretz et al. 2014; Ziv-Gal and Flaws 2016). It has been shown that BPA is able to alter the ovarian development and functions of the ovary through changes in ovarian anatomy and histology and regulation of gene transcription in the ovary (Wu et al. 2020). Likewise, environmentally relevant doses of BPA have been reported to be able to modulate the gene expression profile in epithelial ovarian cancer cells (Hui et al. 2018).

Based on the adverse health effects, the BPA use has become largely restricted. Nevertheless, due to its important role in the plastic industry, manufacturers are employing BPA alternatives. Bisphenol S (BPS) and Bisphenol AF (BPAF) belong to the BPA alternatives in various products, what leads to an increased exposure for humans. Although their chemical structures are similar to BPA, the safety of these related substances was not tested before they were marketed (Rochester and Bolden 2015). BPS is used in the production of food packaging, infant feeding bottles or thermal paper. BPAF, a BPA replacement for crosslinking, is widely used in the manufacture of polyamide and polyester plastics and has been extensively detected in various environmental samples (Chen et al. 2016)

There is no doubt about a real need to replace the molecule of concern with inert or at least less toxic substituents in comparison with the original molecules. Nevertheless, the increasing number of studies has reported the adverse biological effects of different BPA analogs (Grimaldi et al. 2019). These findings highlight the importance to study the actions of other bisphenols (BPs) in various biological systems and models. Despite the fact that many molecular targets of BPs have been described, the complex mechanism of their action as well as their specific pathways, by which they exert their effects, in the majority of cases remains unknown. It is well known that BPs are able to bind to several membrane receptors (Cao et al. 2018) and activate intracellular signaling pathways (Castillo Sanchez et al. 2016; Sauer et al. 2017). BPA has long been emphasized as a xenoestrogen due to its interactions with the estrogen receptors (ERs) $\alpha$ and $\beta$. Thereafter, it has been elucidated that various other nuclear receptors (NRs) are important targets of endocrine disrupting chemicals including BPA and other BPs (Toporova and Balaguer 2020).

NRs are modular proteins composed of several domains, a N-terminal domain harboring ligandindependent activation function, a central DNA binding domain (DBD), and a C-terminal ligand binding domain hosting ligand-dependent transcriptional activation function (Grimaldi et al. 2019). Human NRs represent a superfamily of 48 transcription factors, which are subdivided into several subfamilies (N0-N6) and classes according to their structure similarities, DNA-binding characteristics, and (un)identified endogenous ligands (Meinsohn et al. 2019). NRs regulate gene networks involved in the key physiological processes, such as cell growth and differentiation, development, homeostasis or metabolism. Inappropriate exposure to environmental pollutants, as ligands of NRs, may thus be involved in the proliferative, reproductive, and metabolic diseases. BPs have been shown to target mainly steroid NRs, but they also may interact with orphan NRs. The simultaneous action on several NRs may contribute to the endocrine disrupting mechanism exerted by BPs (Grimaldi et al. 2019).

In the ovarian follicle, the (mural) granulosa cells (GCs) primarily render an endocrine function and support the follicular growth. They both synthesize and respond to steroid hormones in response to various endocrine and paracrine factors. Granulosa cell tumors (GCTs) represent a specific subset of malignant ovarian tumors, which, in contrast to the more common epithelial tumors, arise from the stromal cells of the ovary. GCTs represent appr. 5\% of all malignant ovarian tumors. Although GCTs are generally thought to have a better prognosis than epithelial ovarian tumors, $80 \%$ of patients with advanced tumors die from the disease. GCTs exhibit many morphological, biochemical, and hormonal features of normal proliferating pre-ovulatory GCs (Alexiadis et al. 2011). Unlike the well-examined model of epithelial ovarian cancer, little is known about the molecular and genetic alterations that contribute to the development of GCTs (Ciucci et al. 2018).

While expression and a potential role for several NRs has been previously characterized in the biology of GCs and GCTs, the complex NR presence has not been systematically examined until their profile has been demonstrated in the study of Alexiadis et al. (2011). Although several studies have been focused on the estrogen receptors (ER) $\alpha$ and $\beta$, progesterone receptor, steroidogenic factor-1 (SF-1), liver homolog receptor-1 or peroxisome proliferator-activated receptor (PPAR) $\gamma$ (Alexiadis et al. 2011; Leung et al. 2019; Meinsohn et al. 2019), there is still a limited 
amount of information available regarding the role of NRs in GCTs.

Since it has been shown that BPs are able to interact with NRs and NRs may play a role in the pathogenesis of the ovarian disorders and tumors, we investigated the effects of bisphenol A and its analogs, AF and $S$, on the mRNA expression of selected NRs involved in the steroidogenic and carcinogenic pathways in the human GCT-derived cell line COV434. The six NRs examined in the present study belong to the various NR subgroups: thyroid hormone receptor a (THRA; NR1A1), PPAR $\beta / \delta(P P A R D ; N R 1 C 2)$, retinoid X receptor a $(R X R A ; N R 2 B 1)$, chicken ovalbumin upstream promoter-transcription factor II (COUPTFII; NR2F2), nuclear receptor-related protein 1 (NURR1; NR4A2), and liver receptor homolog-1 (LRH1; NR5A2).

\section{Materials and method}

Chemicals and reagents. Tested chemicals were purchased from Sigma-Aldrich (St. Louis, MO, USA). Bisphenol A (4,4'-isopropylidene-2-diphenol), Bisphenol AF (4-[1,1,1,3,3,3-hexafluoro-2-(4-hydroxyphenyl)propan-2-yl]phenol), and Bisphenol $\mathrm{S}$ (4,4'-sulfonyldiphenol) were initially dissolved in dimethyl sulfoxide (DMSO; Sigma-Aldrich, St. Louis, MO, USA) to stock solutions and the time of use, they were diluted to the required concentrations with the culture medium. The final DMSO concentration in the culture media was $0.1 \%(\mathrm{v} / \mathrm{v})$. Culture media, fetal bovine serum (FBS), and cell culture reagents (L-glutamine, HEPES buffer, penicillin, streptomycin, fungizone) were all purchased from SigmaAldrich (St. Louis, MO, USA).
Cell Culture. The spontaneously immortalized COV434 cell line, derived from a primary human juvenile granulosa cell tumor, was supplied through Sigma-Aldrich from the European Collection of Authenticated Cell Cultures (ECACC) (ECACC 07071909ECACC). The cells were maintained in the Dulbecco's modified Eagle's medium/F12 (DMEM/ F12) culture medium supplemented with 10\% FBS and antibiotics, at $37^{\circ} \mathrm{C}$ in the atmosphere of $5 \%$ $\mathrm{CO}_{2}-95 \%$ air.

Viability assay. COV434 cells were cultured in 96-well plates (TPP AG, Trasadingen, Switzerland) at a density of $5 \times 10^{4}$ cells per well and were treated in with the selected bisphenols at the indicated concentrations $\left(10^{-9}, 10^{-7}, 10^{-5} \mathrm{M}\right)$. Control cells were treated with an equal volume of vehicle alone $(0.1 \%$ DMSO, $\mathrm{v} / \mathrm{v})$. Viability of the cells after $24 \mathrm{~h}$ or $48 \mathrm{~h}$ was monitored by the MTS assay using the CellTiter ${ }^{\circledR} 96$ AQueous One nonradioactive cell proliferation assay (Promega, Madison, WIS, USA) according to the manufacturer's instructions. After $3 \mathrm{~h}$ of culture, absorbance was measured using a microplate reader (BioTek Instruments, Winooski, VT, USA).

RNA extraction and quantitative polymerase chain reaction. COV434 cells were seeded at a density of $3 \times 10^{6}$ cell/well and incubated in 6-well dishes (TPP AG, Trasadingen, Switzerland) with the indicated treatments for $24 \mathrm{~h}$ or $48 \mathrm{~h}$. Total RNA from the cultured cells was extracted using NucleoSpin RNA (MACHEREY-NAGEL, Dueren, Germany) according to the manufacturer's instructions. RNA concentration and quality were assessed using the NanoDrop ND-2000 spectrophotometer (Thermo Scientific, Waltham, MA, USA). Reverse transcription was performed using the RevertAid First Strand

Table 1

The primer sequences used for the RT-qPCR analysis

\begin{tabular}{|c|c|c|c|}
\hline Gene & Oligo sequences $5^{\prime} \rightarrow 3^{\prime}$ & Amplicon length (bp) & Reference \\
\hline THRA & $\begin{array}{l}\text { Fw: AGGTCACCAGATGGAAAGCG } \\
\text { Rv: AGTGATAACCAGTTGCCTTGTC }\end{array}$ & 136 & Lammel Lindeman et al. 2014 \\
\hline PPARD & $\begin{array}{l}\text { Fw: TCATTGCGGCCATCATTCTGT } \\
\text { Rv: TTCGGTCTTCTTGATCCGCT }\end{array}$ & 221 & Inoue et al. 2014 \\
\hline$R X R A$ & $\begin{array}{l}\text { Fw: CTTTTGTTTCCGTTGCTGTTTA } \\
\text { Rv: CTGAGGTCTTTGCTGATGACAC }\end{array}$ & 181 & Hunakova et al. 2016 \\
\hline COUPTFII & $\begin{array}{l}\text { FW: GTGAGGGAGGTGAAAGAACAGG } \\
\text { Rv: GGAAGAAAATCAACAACAACCGA }\end{array}$ & 229 & Pei et al. 2017 \\
\hline NURR1 & $\begin{array}{l}\text { Fw: TTCGCCCCCGGTGAGT } \\
\text { Rv: ATAGTCAGGGTTCGCCTGGAA }\end{array}$ & 106 & Bassett et al. 2004 \\
\hline LRH1 & $\begin{array}{l}\text { Fw: GACCACACCATTCCTCTCCA } \\
\text { Rv: TTAGGTAAGCTGGGCGTTGA }\end{array}$ & 187 & Lefevre et al. 2015 \\
\hline RPL13A & $\begin{array}{l}\text { Fw: CCTGGAGGAGAAGAGGAAAGAGA } \\
\text { Rv: TTGAGGACCTCTGTGTATTTGTCAA }\end{array}$ & 126 & Shah and Faridi 2011 \\
\hline
\end{tabular}


cDNA Synthesis Kit (Thermo Scientific, Waltham, MA, USA), with $0.5 \mu$ g total RNA reverse transcribed using random hexamer primers. qPCR was performed using SensiFast SYBR Hi-ROX Kit (Bioline, London, UK) and the QuantStudio ${ }^{\text {TM }} 5$ Real-Time PCR System (Applied Biosystems, Life Technologies, Carlsbad, CA, USA). The PCR conditions for all transcripts were as follows: polymerase activation at $95^{\circ} \mathrm{C}$ for 3 min, 40 cycles of amplification with denaturation at $95^{\circ} \mathrm{C}$ for $5 \mathrm{~s}$, and annealing and extension at $60^{\circ} \mathrm{C}$ for $20 \mathrm{~s}$. Genes were amplified in duplicates. Relative changes in mRNA expression were calculated by the $2^{-\Delta \Delta \mathrm{Ct}}$ method (Livak and Schmittgen 2001) using RPL13A as the reference gene. The primer pairs for the selected NRs (Sigma-Aldrich, Darmstadt, Germany) used for qPCR analysis are summarized in the Table 1.

Statistical analysis. The data are presented as mean \pm standard error of the mean (SEM) of 4 independent experiments. Data were analyzed by one-way ANOVA, and Tukey-Kramer Multiple Comparisons post-test was performed using GraphPad InStat version 3.05 (GraphPad Software, Inc.; San Diego, CA, USA) to identify statistical differences between relevant groups. Differences were considered to be significant when $\mathrm{p}<0.05$.

\section{Results}

Effect of bisphenols on COV434 cell viability. With the aim to determine whether the selected BPs are able to influence viability of the human granu-

Table 2

Effect of Bisphenol A (BPA) and its analogs Bisphenol AF (BPAF) and Bisphenol S (BPS) on viability of the COV434 cells treated with different concentrations of the agents for $24 \mathrm{~h}$ and $48 \mathrm{~h}$ periods

\begin{tabular}{lccc}
\hline \multirow{2}{*}{ Group } & & \multicolumn{2}{c}{ Viability (\%) } \\
\cline { 3 - 4 } & & $\mathbf{2 4 h}$ & $\mathbf{4 8 ~ h}$ \\
\hline Control & & $100.0 \pm 4.8$ & $100.0 \pm 6.6$ \\
& $10^{-9} \mathrm{M}$ & $98.7 \pm 6.1$ & $103.8 \pm 6.9$ \\
BPA & $10^{-7} \mathrm{M}$ & $100.8 \pm 6.2$ & $102.0 \pm 6.2$ \\
& $10^{-5} \mathrm{M}$ & $94.1 \pm 6.4$ & $104.1 \pm 5.9$ \\
& $10^{-9} \mathrm{M}$ & $103.5 \pm 5.5$ & $105.0 \pm 4.2$ \\
BPF & $10^{-7} \mathrm{M}$ & $103.1 \pm 5.4$ & $97.1 \pm 5.6$ \\
& $10^{-5} \mathrm{M}$ & $97.3 \pm 4.9$ & $87.8 \pm 6.5$ \\
& $10^{-9} \mathrm{M}$ & $102.3 \pm 6.4$ & $100.3 \pm 5.5$ \\
BPS & $10^{-7} \mathrm{M}$ & $103.6 \pm 5.2$ & $97.2 \pm 6.0$ \\
& $10^{-5} \mathrm{M}$ & $101.3 \pm 5.7$ & $88.6 \pm 9.5$ \\
\hline
\end{tabular}

Data represent the mean \pm SEM of 4 independent experiments. losa COV434 cell line, the cells were incubated with the three different concentrations $\left(10^{-9}, 10^{-7}\right.$, and $10^{-5} \mathrm{M}$ ) of BPA, BPAF or BPS for 24 and $48 \mathrm{~h}$ periods. Neither of the bisphenols used altered the COV434 cell viability after $24 \mathrm{~h}$ treatment. Likewise, the cell viability was not markedly impaired in the presence of any of BPs after $48 \mathrm{~h}$, even when used at the highest concentrations (Table 2).

Effect of bisphenols on mRNA expression of selected nuclear receptors in COV434 cells. To investigate the effects of the BPs on the gene expression of the selected NRs, COV434 cells were treated with the three different concentrations $\left(10^{-9}, 10^{-7}\right.$, and $10^{-5} \mathrm{M}$ ) of BPA, BPAF or BPS, for 24 and $48 \mathrm{~h}$ periods. We examined mRNA expression of the six NRs from various NR subgroups: THRA, PPARD, RXRA, COUPTFI, NURR1, and LRH1. The expression of these genes in BPs-treated COV434 cells has been compared with the solvent-treated control cells.

After $24 \mathrm{~h}$ period, neither of the NRs expression was significantly changed in COV434 cells by the treatment with either BPA or its analogs BPAF or BPS (Figures 1-3). Likewise, the expression of the selected genes was not markedly altered by the lower $\left(10^{-9} \mathrm{M}\right.$ and $10^{-7} \mathrm{M}$; Figures $\left.1 \mathrm{~A}, 2,3 \mathrm{~B}\right)$ or highest BPs concentrations $\left(10^{-5} \mathrm{M}\right.$; Figures $\left.1 \mathrm{~A}, 2,3 \mathrm{~B}\right)$ after $48 \mathrm{~h}$. However, both BPAF and BPS at the highest tested concentration $\left(10^{-5} \mathrm{M}\right)$ significantly upregulated $(\mathrm{p} \leq 0.05)$ the mRNA expression levels of the two NRs, PPARD (Figure 1B) and NURR1 (Figure 3A) in the COV434 cells at the time point $48 \mathrm{~h}$. Nevertheless, significant upregulation of these genes was not observed in the BPA-treated groups (Figures 1-3).

\section{Discussion}

Nuclear receptors play a fundamental role in many aspects of cellular metabolism, homeostasis, and proliferation. Furthermore, they have been revealed to be an important target of bisphenols. In the present study, we investigated whether BPA and its analogs BPAF and BPS might influence the mRNA expression of the selected NRs (LRH1, NURR1, THRA, COUPTF2, PPARD, RXRA, RARA), which were previously shown to be expressed in the human granulosa cell line COV434 (Alexiadis et al. 2011).

Thyroid hormone receptors (TRs) members of the NR1A family of NRs are expressed in a wide range of tissues including ovarian GCs and GCTs. Triiodothyronine acting through the TRs is considered to be a biological amplifier of the stimulatory action of gonadotropins on GC functions (Vissenberg et al. 2015). Recently, it has been shown that isoforms 


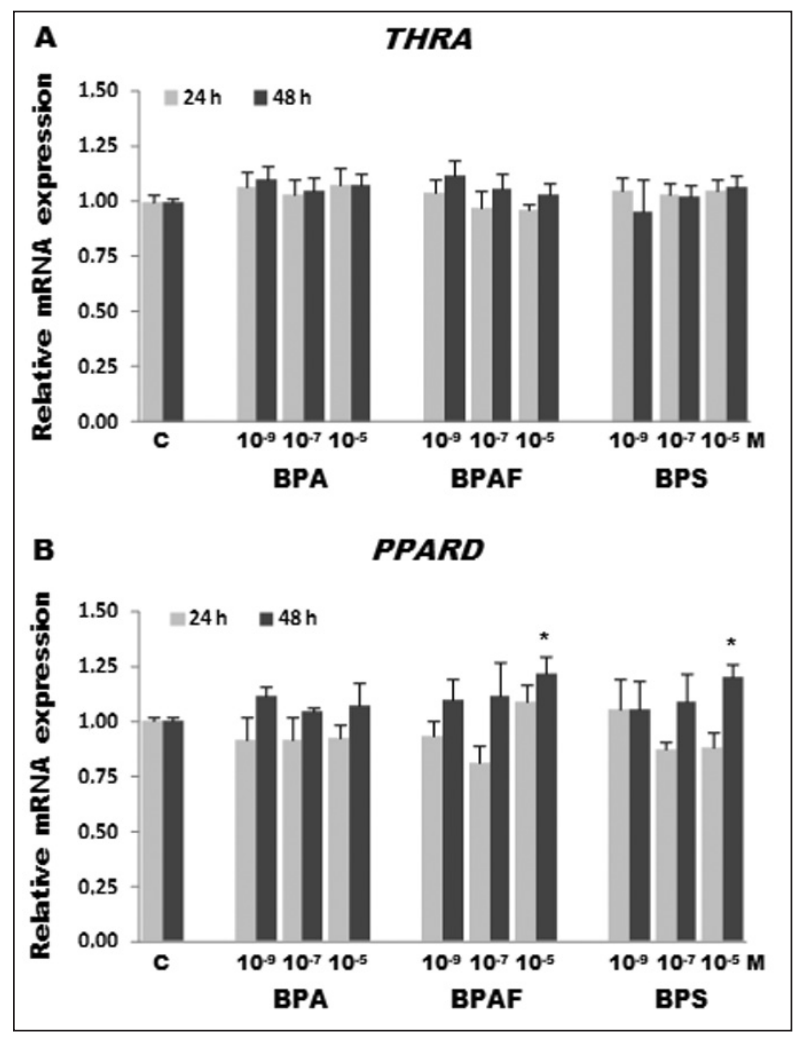

Figure 1. Effect of Bisphenol A (BPA) and its analogs Bisphenol AF (BPAF) and Bisphenol S (BPS) on mRNA expression of (A) thyroid hormone receptor a (THR) and (B) peroxisomeproliferator activating receptor $\beta / \delta$ (PPARD) in the COV434 cells treated with different concentrations of the agents for 24 $\mathrm{h}$ and $48 \mathrm{~h}$ periods. Statistically significant differences are indicated by ${ }^{*} \mathrm{p}<0.05$ (compared with control cells). Data represent the mean \pm SEM of 4 independent experiments.

of TRa may provide prognostic information for ovarian cancer patients (Ditsch et al. 2020). It has been reported that BPs might alter THRA expression depending on the cell type and species, e.g. THRA has been shown to be upregulated after exposure to BPA in the human prostate cells (Renaud et al. 2019), while different BPs suppressed tr $\alpha$ expression in rat pituitary cells (Lee et al. 2017). However, our study did not reveal any changes in THRA expression after BPs treatment at any concentration or the time points studied.

In the GCTs, the expression of all three PPAR genes $(\alpha, \delta / \beta$, and $\gamma$ ) was observed with PPAR $\gamma$ expression being particularly abundant. Several studies have demonstrated a role for PPAR $\gamma$ in the inhibition of proliferation and induction of apoptosis in cultured rat GCs. However, in the COV434 cell line, the expression of PPAR $\gamma$ is almost absent. On the other hand, although PPAR $\delta$ levels in the GCTs are 4-fold lower

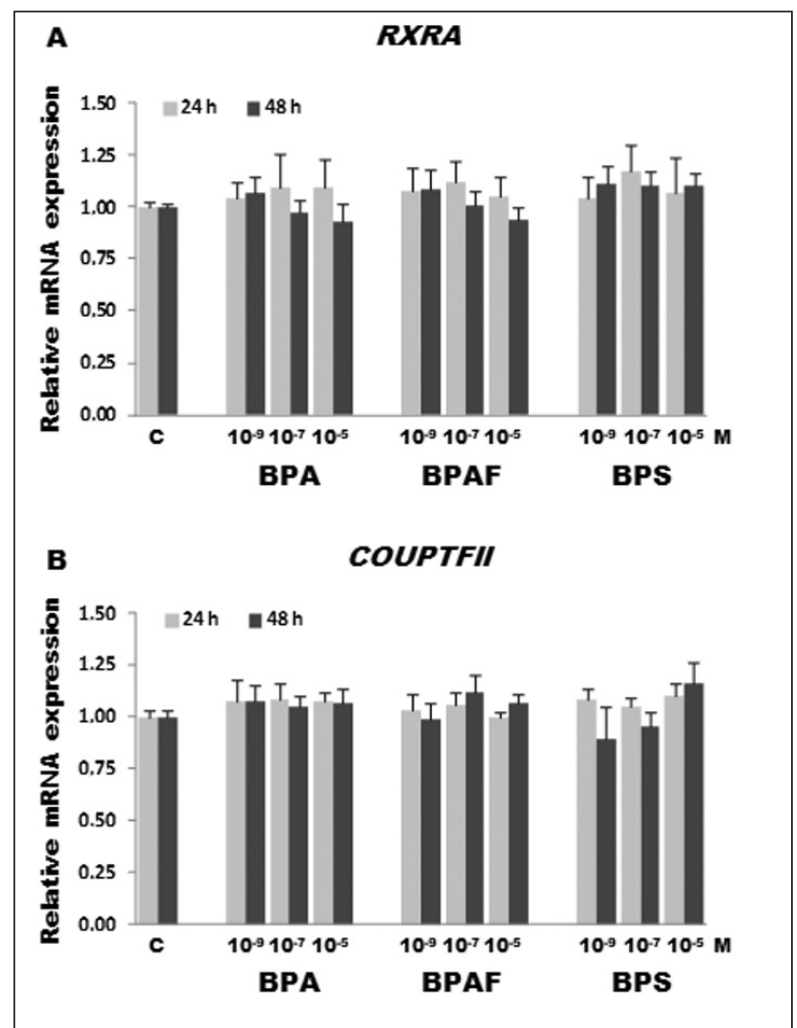

Figure 2. Effect of Bisphenol A (BPA) and its analogs Bisphenol AF (BPAF) and Bisphenol S (BPS) on mRNA expression of $(\mathrm{A})$ retinoid $\mathrm{X}$ receptor $a(R X R A)$ and $(\mathrm{B})$ chicken ovalbumin upstream promoter-transcription factor II (COUPTFII) in the COV434 cells treated with different concentrations of the agents for $24 \mathrm{~h}$ and $48 \mathrm{~h}$ periods. Data represent the mean \pm SEM of 4 independent experiments.

than those of PPAR $\gamma$, their levels in the COV434 cells are significantly higher in comparison with those of PPAR $\gamma$ (Alexiadis et al. 2011). Regulation of PPARD expression in ovarian follicles is dependent on gonadotropins (Kulus et al. 2020). PPAR $\delta / \beta$ has pleiotropic effects on cell homeostasis and energy utilization and may play different roles in various types of cancer (Martin-Martin et al. 2018; Liu et al. 2019). In mouse tumor Leydig cells treated with distinct BPA derivatives, different effects on PPAR $\delta / \beta$ expression have been found (Gorowska-Wojtowicz et al. 2019). The present results show that the highest concentrations of BPAF and BPS were able to upregulate PPARD expression after $48 \mathrm{~h}$ of treatment.

COUP-TFII is a ubiquitously expressed orphan member of the NR2 family and is the most abundantly expressed NR in the GCTs and in GC lines COV434 and KGN (Alexiadis et al. 2011). The role of COUP-TFII in GCs has been reported to negatively 


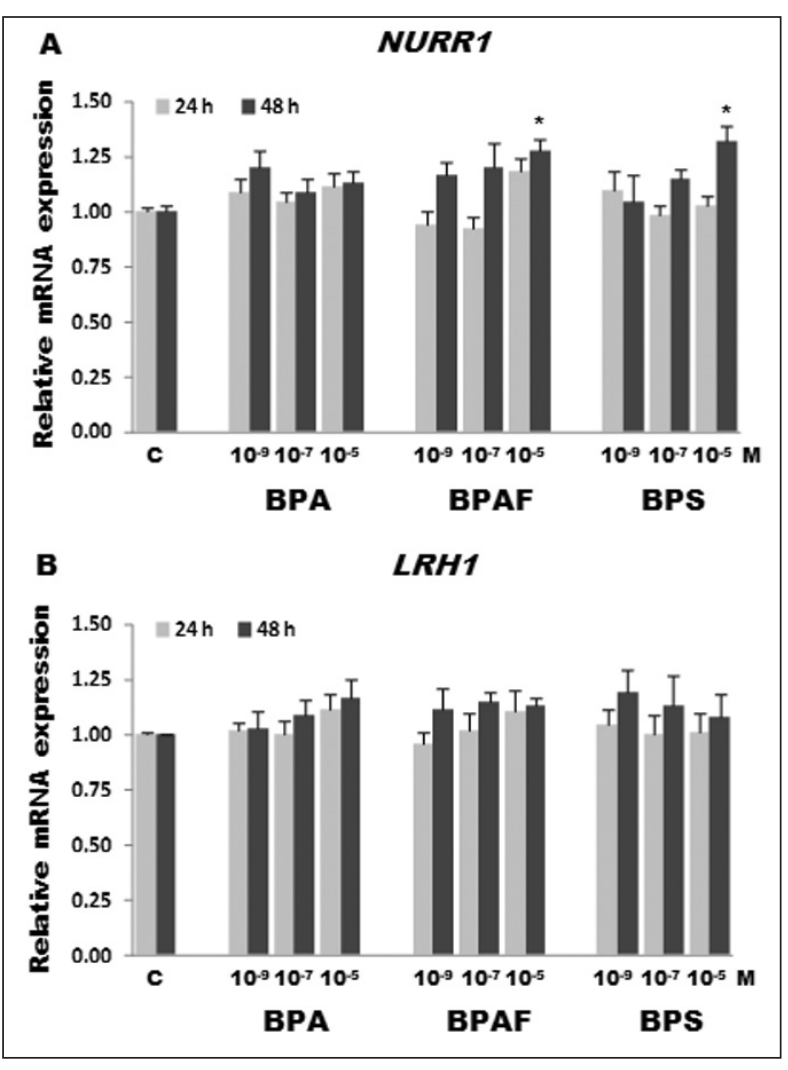

Figure 3. Effect of Bisphenol A (BPA) and its analogs Bisphenol AF (BPAF) and Bisphenol S (BPS) on mRNA expression of (A) nuclear receptor-related protein 1 (NURR1) and (B) liver receptor homolog-1 (LRH1) in the COV434 cells treated with different concentrations of the agents for $24 \mathrm{~h}$ and $48 \mathrm{~h}$ periods. Statistically significant differences are indicated by ${ }^{*} \mathrm{p}<0.05$ (compared with control cells). Data represent the mean \pm SEM of 4 independent experiments.

regulate SF-1-dependent transcription of steroidogenic enzymes (Alexiadis et al. 2011). COUP-TFII is differentially expressed in normal ovarian stromal (high) and epithelial (low) cells, while in ovarian tumors, this expression pattern has been shown to be reversed (Safe et al. 2014). COUP-TFII regulates the expression of several genes and pathways in ovarian cancer cells indicating the importance of cancer cell context on the role of this NR. The studies have suggested the pro-oncogenic activity for COUP-TFII for breast, pancreatic, and prostate cancer, whereas in the ovarian epithelial cancer cells, the knockdown of COUP-TFII increased apoptosis in the cells (Safe et al. 2014). In our study, however, we did not observe significant alterations of COUPTFII expression after the treatment with either BPA or its analogs BPAF and BPS. Nevertheless, these are the first data investigating the possible influence of BPs on this NR.
RXRs members of the NR2B family form heterodimers with a number of NRs. Particularly as the heterodimers with PPAR $\gamma$ and liver $\mathrm{X}$ receptor, they are involved in the regulation of steroid synthesis in human GCs (Yanase et al. 2001; Yoo et al. 2011). In ovarian epithelial cancer cells, RXRa plays an important role in mediating growth suppression by retinoic acid (Wu et al. 1998). There is also abundant expression of RXRa in the COV434 cells (Alexiadis et al. 2011). Previously, it was shown that BPA may alter the expression of RXRa in murine embryos (Nishizawa et al. 2005) and that RXRs may be targeted by various BPs (Sharma et al. 2018). Our results did not show any significant changes in RXRA expression after exposure of COV434 cells to individual bisphenols.

The orphan receptor Nurrl belongs to the NR4A subgroup, which members are classified as immediate early response genes because their expression is rapidly induced by a variety of physiological stimuli including peptide hormones like gonadotropins and are considered important ovarian factors in regulation of female reproduction. NURR1 has been shown to suppress the transcription of aromatase in the KGN granulosa-like tumor cells and conversely, reduces the endogenous NURR1 elevated aromatase gene expression. Such findings suggest a causal relationship between the rapid decline of aromatase mRNA and the induction of NR4A expression occurring upon luteinization hormone surge at the later stages of follicular development (Wu et al. 2005; Wu et al. 2015). Nurrl has been implicated in cancer progression although the distinct roles of Nurrl in different tissues point to possible context-dependent effects of this transcription factor (Beard et al. 2015). We found that after $48 \mathrm{~h}$ treatment with the highest concentration of BP analogs BPAF and BPS, NURR1 expression was significantly higher compared to controls. To our knowledge, this is the first result describing the effect of BPs with respect to this orphan NR.

The NR5A protein LRH-1, has an important role in the ovarian function, particularly in the progesterone production by GCs. Both the COV434 cells and the GCTs have abundant LRH-1 expression. LRH-1 synergizes with the transcription factor GATA4 in the regulation of the inhibin a-promoter, and upregulated GATA4 expression is thought to have a role in the pathogenesis of GCTs (Alexiadis et al. 2011). Although LRH-1 is overexpressed in GCTs compared to normal human ovary (Chand et al. 2013) and appears to be a potent impetus for cell proliferation, its significance in GCTs has not been defined (Meinsohn et al. 2019). The BP influence on LRH-1 has not been examined yet. In our study, the mRNA 
levels of $L R H 1$ were not significantly changed by any of the BPs treatment.

So far, the actions of BPs on NRs have been studied and confirmed predominantly on steroid NRs (ERs, androgen, and progesterone receptors). However, several other NRs (PPARs, TRs, RXRs, etc.) may also be targeted by BPs (Toporova and Balaguer 2020). As noted above, effects of BPs on some NRs (COUPTFII, Nurr1, LRH-1) are investigated for the first time in our study. Among the BP derivatives examined in previous studies, halogenated BPs including fluorinated BPAF seem to exert the most potent actions (Grimaldi et al. 2019) what is in accord with our observation for this BP derivative.

In summary, in the present study, we did not observe that BPs concentrations used may provoke changes in the expression of the selected NRs in
COV434 cells; however, at specific concentrations and time points they might alter mRNA expression of certain NRs (NURR1, PPARD). Possible alterations might result in providing abundant sites for bisphenol actions in the ovarian follicles or tumors; however, to prove such a hypothesis and the biological consequences, a number of further studies, including binding and transactivation assays, are needed. As well, the biological significance of the interference of BPs with NRs is far from complex understanding.

\section{Acknowledgements}

This work was supported by the VEGA grant 2/0074/18 and the Slovak Research and Development Agency under the contract No. APVV-18-0150.

\section{References}

Alexiadis M, Eriksson N, Jamieson S, Davis M, Drummond AE, Chu S, Clyne CD, Muscat GE, Fuller PJ. Nuclear receptor profiling of ovarian granulosa cell tumors. Horm Cancer 2, 157-169, 2011.

Bassett MH, Suzuki T, Sasano H, De Vries CJ, Jimenez PT, Carr BR, Rainey WE. The orphan nuclear receptor NGFIB regulates transcription of 3beta-hydroxysteroid dehydrogenase. Implications for the control of adrenal functional zonation. J Biol Chem 279, 37622-37630, 2004.

Beard JA, Tenga A, Chen T. The interplay of NR4A receptors and the oncogene-tumor suppressor networks in cancer. Cell Signal 27, 257-266, 2015.

Cao Y, Qu X, Ming Z, Yao Y, Zhang Y. The correlation between exposure to BPA and the decrease of the ovarian reserve. Int J Clin Exp Pathol 11, 3375-3382, 2018.

Castellini C, Totaro M, Parisi A, D’Andrea S, Lucente L, Cordeschi G, Francavilla S, Francavilla F, Barbonetti A. Bisphenol A and Male Fertility: Myths and Realities. Front Endocrinol (Lausanne) 11, 353, 2020.

Castillo Sanchez R, Gomez R, Perez Salazar E. Bisphenol A induces migration through a GPER-, FAK-, Src-, and ERK2-dependent pathway in MDA-MB-231 breast cancer cells. Chem Res Toxicol 29, 285-295, 2016.

Chand AL, Pathirage N, Lazarus K, Chu S, Drummond AE, Fuller PJ, Clyne CD. Liver receptor homologue-1 expression in ovarian epithelial and granulosa cell tumours. Steroids 78, 700-706, 2013.

Chen D, Kannan K, Tan H, Zheng Z, Feng YL, Wu Y, Widelka M. Bisphenol analogues other than BPA: environmental occurrence, human exposure, and toxicity-a review. Environ Sci Technol 50, 5438-5453, 2016.

Ciucci A, Ferrandina G, Mascilini F, Filippetti F, Scambia G, Zannoni GF, Gallo D. Estrogen receptor $\beta$ : Potential target for therapy in adult granulosa cell tumors? Gynecol Oncol 150, 158-165, 2018.

Ditsch N, Heublein S, Jeschke U, Sattler C, Kuhn C, Hester A, Czogalla B, Trillsch F, Mahner S, Engel J, Mayr D, Schmoeckel E. Cytoplasmic versus nuclear THR alpha expression determines survival of ovarian cancer patients. J Cancer Res Clin Oncol 146, 1923-1932, 2020.

Gerona RR, Pan J, Zota AR, Schwartz JM, Friesen M, Taylor JA, Hunt PA, Woodruff TJ. Direct measurement of Bisphenol A (BPA), BPA glucuronide and BPA sulfate in a diverse and low-income population of pregnant women reveals high exposure, with potential implications for previous exposure estimates: a cross-sectional study. Environ Health 15, 50, 2016.

Gorowska-Wojtowicz E, Duliban M, Kudrycka M, Dutka P, Pawlicki P, Milon A, Zarzycka M, Placha W, KotulaBalak M, Ptak A, Wolski JK, Bilinska B. Leydig cell tumorigenesis - implication of G-protein coupled membrane estrogen receptor, peroxisome proliferator-activated receptor and xenoestrogen exposure. In vivo and in vitro appraisal. Tissue Cell 61, 51-60, 2019.

Grimaldi M, Boulahtouf A, Toporova L, Balaguer P. Functional profiling of bisphenols for nuclear receptors. Toxicology 420, 39-45, 2019. 
Hui L, Li H, Lu G, Chen Z, Sun W, Shi Y, Fu Z, Huang B, Zhu X, Lu W, Xia D, Wu Y. Low dose of bisphenol A modulates ovarian cancer gene expression profile and promotes epithelial to mesenchymal transition via canonical Wnt pathway. Toxicol Sci 164, 527-538, 2018.

Hunakova L, Macejova D, Toporova L, Brtko J. Anticancer effects of tributyltin chloride and triphenyltin chloride in human breast cancer cell lines MCF-7 and MDA-MB-231. Tumour Biol 37, 6701-6708, 2016.

Inoue T, Kohro T, Tanaka T, Kanki Y, Li G, Poh HM, Mimura I, Kobayashi M, Taguchi A, Maejima T, Suehiro J, Sugiyama A, Kaneki K, Aruga H, Dong S, Stevens JF, Yamamoto S, Tsutsumi S, Fujita T, Ruan X, Aburatani H, Nangaku M, Ruan Y, Kodama T, Wada Y. Cross-enhancement of ANGPTL4 transcription by HIF1 alpha and PPAR beta/delta is the result of the conformational proximity of two response elements. Genome Biol, 15, R63, 2014

Kulus M, Kranc W, Sujka-Kordowska P, Celichowski P, Konwerska A, Jankowski M, Jeseta M, Skowronski MT, Piotrowska-Kempisty H, Bukowska D, Zabel M, Bruska M, Mozdziak P, Kempisty B, Antosik P. Transcriptomic analysis of expression of genes regulating cell cycle progression in porcine ovarian granulosa cells during short-term in vitro primary culture. Histochem Cell Biol 153, 397-412, 2020.

Lammel Lindemann JA, Angajala A, Engler DA, Webb P, Ayers SD. Thyroid hormone induction of human cholesterol 7 alpha-hydroxylase (Cyp7a1) in vitro. Mol Cell Endocrinol 388, 32-40, 2014.

Lathi RB, Liebert CA, Brookfield KF, Taylor JA, vom Saal FS, Fujimoto VY, Baker VL. Conjugated bisphenol A in maternal serum in relation to miscarriage risk. Fertil Steril 102, 123-128, 2014.

Lee S, Kim C, Youn H, Choi K. Thyroid hormone disrupting potentials of bisphenol A and its analogues - in vitro comparison study employing rat pituitary (GH3) and thyroid follicular (FRTL-5) cells. Toxicol In Vitro 40, 297-304, 2017.

Lefevre L, Authier H, Stein S, Majorel C, Couderc B, Dardenne C, Eddine MA, Meunier E, Bernad J, Valentin A, Pipy B, Schoonjans K, Coste A. LRH-1 mediates anti-inflammatory and antifungal phenotype of IL-13-activated macrophages through the PPAR $\gamma$ ligand synthesis. Nat Commun 6, 6801, 2015.

Leung DTH, Nguyen T, Oliver EM, Matti J, Alexiadis M, Silke J, Jobling TW, Fuller PJ, Chu S. Combined PPAR $\gamma$ activation and XIAP inhibition as a potential therapeutic strategy for ovarian granulosa cell tumors. Mol Cancer Ther 18, 364-375, 2019.

Liu Y, Deguchi Y, Tian R, Wei D, Wu L, Chen W, Xu W, Xu M, Liu F, Gao S, Jaoude JC, Chrieki SP, Moussalli MJ, Gagea M, Morris J, Broaddus RR, Zuo X, Shureiqi I. Pleiotropic Effects of PPARD Accelerate colorectal tumorigenesis, progression, and invasion. Cancer Res 79, 954-969, 2019.

Livak KJ, Schmittgen TC. Analysis of relative gene expression data using real-time quantitative PCR and the 2(-Delta Delta C(T)) Method. Methods 25, 402-408, 2001.

Martin-Martin N, Zabala-Letona A, Fernandez-Ruiz S, Arreal L, Camacho L, Castillo-Martin M, Cortazar AR, Torrano V, Astobiza I, Zuniga-Garcia P, Ugalde-Olano A, Loizaga-Iriarte A, Unda M, Valcarcel-Jimenez L, Arruabarrena-Aristorena A, Piva M, Sanchez-Mosquera P, Aransay AM, Gomez-Munoz A, Barrio R, Sutherland JD, Carracedo A. PPAR $\delta$ elicits ligand-independent repression of trefoil factor family to limit prostate cancer growth. Cancer Res 78, 399-409, 2018.

Meinsohn MC, Smith OE, Bertolin K, Murphy BD. The orphan nuclear receptors steroidogenic factor-1 and liver receptor homolog-1: structure, regulation, and essential roles in mammalian reproduction. Physiol Rev 99, 1249-1279, 2019.

Nishizawa H, Morita M, Sugimoto M, Imanishi S, Manabe N. Effects of in utero exposure to bisphenol A on mRNA expression of arylhydrocarbon and retinoid receptors in murine embryos. J Reprod Dev 51, 315-324, 2005.

Nomiri S, Hoshyar R, Ambrosino C, Tyler CR, Mansouri B. A minireview of bisphenol A (BPA) effects on cancerrelated cellular signaling pathways. Environ Sci Pollut Res Int 26, 8459-8467, 2019.

Pei F, Jiang J, Bai S, Cao H, Tian L, Zhao Y, Yang C, Dong H, Ma Y. Chemical-defined and albumin-free generation of human atrial and ventricular myocytes from human pluripotent stem cells. Stem Cell Res 19, 94-103, 2017.

Peretz J, Vrooman L, Ricke WA, Hunt PA, Ehrlich S, Hauser R, Padmanabhan V, Taylor HS, Swan SH, VandeVoort CA, Flaws JA. Bisphenol a and reproductive health: update of experimental and human evidence, 2007-2013. Environ Health Perspect 122, 775-786, 2014.

Renaud L, Huff M, da Silveira WA, Angert M, Haas M, Hardiman G. Genome-wide analysis of low dose bisphenol-A (BPA) exposure in human prostate cells. Curr Genomics 20, 260-274, 2019.

Rochester J, Bolden A. Bisphenol S and F: A systematic review and comparison of the hormonal activity of bisphenol A substitutes. Environ Health Perspect 123, 643-650, 2015.

Safe S, Jin UH, Hedrick E, Reeder A, Lee SO. Minireview: role of orphan nuclear receptors in cancer and potential as drug targets. Mol Endocrinol 28, 157-172, 2014. 
Sauer SJ, Tarpley M, Shah I, Save AV, Lyerly HK, Patierno SR, Williams KP, Devi GR. Bisphenol A activates EGFR and ERK promoting proliferation, tumor spheroid formation and resistance to EGFR pathway inhibition in estrogen receptor-negative inflammatory breast cancer cells. Carcinogenesis 38, 252-260, 2017.

Scsukova S, Rollerova E, Bujnakova Mlynarcikova A. Impact of endocrine disrupting chemicals on onset and development of female reproductive disorders and hormone-related cancer. Reprod Biol 16, 243-254, 2016.

Shah K, Faridi J. Estrogen, tamoxifen, and Akt modulate expression of putative housekeeping genes in breast cancer cells. J Steroid Biochem Mol Biol 125, 219-225, 2011.

Sharma S, Ahmad S, Khan MF, Parvez S, Raisuddin S. In silico molecular interaction of bisphenol analogues with human nuclear receptors reveals their stronger affinity vs. classical bisphenol A. Toxicol Mech Methods 28, 660-669, 2018.

Toporova L, Balaguer P. Nuclear receptors are the major targets of endocrine disrupting chemicals. Mol Cell Endocrinol 502, 110665, 2020.

Vissenberg R, Manders VD, Mastenbroek S, Fliers E, Afink GB, Ris-Stalpers C, Goddijn M, Bisschop PH. Pathophysiological aspects of thyroid hormone disorders/thyroid peroxidase autoantibodies and reproduction. Hum Reprod Update 21, 378-387, 2015.

Wu F, Zhao J, Zhang E, Wu Q, Wu X, Zhang D, Liu Y, Wang R, Li W. Bisphenol A affects ovarian development in adolescent mice caused by genes expression change. Gene 740, 144535, 2020.

Wu S, Zhang D, Zhang ZP, Soprano DR, Soprano KJ. Critical role of both retinoid nuclear receptors and retinoid$\mathrm{X}$-receptors in mediating growth inhibition of ovarian cancer cells by all-trans retinoic acid. Oncogene 17, 2839-2849, 1998.

Wu S, Sun H, Zhang Q, Jiang Y, Fang T, Cui I, Yan G, Hu Y. MicroRNA-132 promotes estradiol synthesis in ovarian granulosa cells via translational repression of Nurr1. Reprod Biol Endocrinol 13, 94, 2015.

Wu Y, Ghosh S, Nishi Y, Yanase T, Nawata H, Hu T. The orphan nuclear receptors NURR1 and NGFI-B modulate aromatase gene expression in ovarian granulosa cells: a possible mechanism for repression of aromatase expression upon luteinizing hormone surge. Endocrinology 146, 237-246, 2005.

Yanase T, Mu YM, Nishi Y, Goto K, Nomura M, Okabe T, Takayanagi R, Nawata H. Regulation of aromatase by nuclear receptors. J Steroid Biochem Mol Biol 79, 187-192, 2001.

Yoo SW, Savchev S, Sergott L, Rezai T, Lopez MF, Von Wald T, Eaton JL, Reindollar R, Usheva A. A large network of interconnected signaling pathways in human ovarian follicles is supported by the gene expression activity of the granulosa cells. Reprod Sci 18, 476-484, 2011.

Ziv-Gal A, Flaws JA. Evidence for bisphenol A-induced female infertility: a review (2007-2016). Fertil Steril 106, 827-856, 2016. 